\title{
Preliminary studies on the occurrence of nonylphenol in the marine environments, Chennai-a case study
}

\author{
Subha Raju, Madhumathi Sivamurugan, Karuna Gunasagaran, Thirunavukkarasu Subramani \\ and Munuswamy Natesan
}

\begin{abstract}
Background: Resisting degradation, nonylphenol (NP) remains as a critical compound contaminating many habitats. Prevalence of nonylphenol in the ecosystem of Indian coastlines is not well documented as that of fresh water. Hence, the present study was intended to estimate the concentration of nonylphenol from water and sediments samples of Chennai (Madras) coastline which is polluted with anthropogenic activities from the city.

Results: Six stations were sampled such as Ennore mouth, Ennore creek, Kasimedu, Marina, Besant Nagar, and Muttukaadu which covered approx. $50 \mathrm{~km}$ of south-east coastline. Nonylphenol was extracted from water and sediment samples by liquid and solid phase extraction respectively and quantified using gas chromatogram coupled mass spectrum (GC-MS). All the sites were contaminated with nonylphenol (NP) of which at Ennore mouth, concentrations were above the United States Environmental Protection Agency (US EPA) prescribed environmental safety limit of $1.7 \mu \mathrm{g} / \mathrm{l}$. Nonylphenol concentrations varied, and higher levels were observed in sediment samples compared to water. Occurrence of NP ranged from 1.22 to $7.24 \mu \mathrm{g} / \mathrm{l}$ in water and 3.31 to 30 . $96 \mu \mathrm{g} / \mathrm{kg}$ in sediments.

Conclusion: To our knowledge, this is the first report on the presence of NP in the marine environments of Chennai (Madras). This study alarms increase in the concentration of nonylphenol in the marine environments of Chennai coast as the measured values are several magnitudes higher than the environmental safety limit proposed by the US EPA.
\end{abstract}

Keywords: Nonylphenol, Water, Endocrine disruptor, Chennai, Sediments

\section{Background}

Continuous expulsion of pollutants into aquatic systems in India has prompted a more sensitive assessment on the level of pollutants inhabiting the environment. In recent ecotoxicological research, there is an increasing concern over the emerging endocrine-disrupting compounds (EDCs) in the environment due to its multiple effects especially on health and reproduction of wildlife and humans. They exert physiological effects by mimicking the natural hormone or by interfering with hormone's production, release, metabolism, and elimination (Tabb \& Blumberg, 2006). There are several natural and

\footnotetext{
* Correspondence: munuswamynm@yahoo.com

Department of Zoology, University of Madras, Life Science Building, Guindy Campus, Chennai, India
} under the family of Alkylphenol ethoxylates (APEOs) such as nonylphenol ethoxylates (NPEs) and octylphenol ethoxylates (OPEs) with the former captivating $80 \%$ of the world's market and octylphenol holds the remaining 20\% (White, Jobling, Hoare, Sumpter, \& Parker, 1994). In the environment due to several natural factors, NPEs are broken down to nonylphenol (NP) which has been predicted to be more harmful than the parent compound itself.

Nonylphenol is a viscous, pale yellow color product of industrial synthesis formed during the alkylation process of phenols. Nonylphenol is not a single chemical compound; instead, the term refers to compounds of those that have a central aromatic (or benzene) ring and a nine carbon side chain. The most commonly occurring compound of 
nonylphenol is 4-nonylphenol, in which the side chains are attached directly to the carbon opposite of the hydroxyl group $(\mathrm{OH}$; oxygen and a hydrogen atom) and this compound makes up over $90 \%$ of commercial nonylphenol. NPs are widely used as detergents, emulsifiers, and surfactants (wetting agents) in household and industrial products such as paints, plastics, cosmetics, lubricant oils, construction materials, vulcanized rubber, and paper. They are also used in the processing of fuels, metals, petroleum, textiles, agricultural chemicals, and leather. Substantial quantities of $\mathrm{NP}$-containing compounds reach sewage treatment works, where they biodegrade into several by-products, including NP (Agency, 2010). Further instance, un-reacted NP used as stabilizer in plastic may leach out, and though this might not be a significant source of NP in the environment, it can be direct route of exposure. When it comes in close contact with foods or if the plastics are ingested by aquatic organisms, they may cause serious effects.

Due to its physico-chemical characteristics such as low water solubility, nonylphenol accumulates in environmental compartments like sewage sludge, river sediment is moderately persistent and its occurrence is clearly correlated with human activities such as wastewater treatment, land filling, and sewage sludge recycling. Nonylphenol is taken up from water and sediment by aquatic biota (Jim Carlisle, David Chan, Page Painter, \& Wu, 2009), moderately bio-accumulative, and can move up the food chain, but does not biomagnify to any great degree yet extremely toxic to aquatic organisms (Agency, 2010).

Nonylphenol is ubiquitous in several environmental matrices accounting to their endocrine disruptor (ED) potential; the usage is partially banned in Canada and completely banned in European Union (Nair-Menon, Campbell, \& Blake, 1996; Renner, 1997; Soto, Justicia, Wray, \& Sonnenschein, 1991) especially para-NP has been banned since 2003 due to its high toxicity to invertebrates and estrogenic activity in vertebrates. However, in developing countries, the demand is uprising around $2 \%$ annually. Without any regulations for NP use, its effects are completely ignored as no major incidence is accounted. Apart from NP, unawareness on emerging chemicals such as APEOs, plasticizers, and phthalates from pharmaceutical and personal care products is also of major concern (Duong et al., 2010). Chennai being the largest and capital city of Tamilnadu is unaware of NP present in its environment, and to our knowledge, there are no reports made or efforts taken to monitor. Hence, this study was intended to provide preliminary report on the levels of nonylphenol in Chennai (Madras) coastline.

\section{Materials and methods \\ Description of study area}

The study was conducted on Chennai coastline, the fourth largest city in India also known as "The Gateway of South India." Due to urbanization in various industrial and residential sectors, the city's waste is disposed into the rivers such as Adyar, Cooum, Kosasthalaiyar, and Buckingham canal where the contaminants reach the sea finally. This study conducted a preliminary analysis on the concentration of nonylphenol in the water and sediment samples from the mouth of these rivers that drain their polluted waters into the sea. Six stations, covering the Chennai coast, were chosen (Fig. 1) covering approximately $50 \mathrm{~km}$ coastline. Four stations Ennore, Marina, Besant Nagar, and Muttukadu are places which receive effluents from the city from these rivers. The other two stations were Ennore creek, upstream of the river, and a commercial fishing harbor of the city, Kasimedu.

\section{Sampling}

Surface water samples from Muttukadu, Besant Nagar, Marina, Kasimedu, Ennore, and Ennore creek were collected in summer 2014 using 2-1 amber glass bottles. The surface sediment samples were collected using Van Veen stainless steel mud grab from the sampling stations which included the clayey samples of Ennore and Muttukadu and sandy samples of Ennore creek, Kasimedu, Marina, and Besant Nagar. Samples were placed on ice and transferred to lab and stored at $-20^{\circ} \mathrm{C}$ until extraction. Details of sampling locations are shown in Fig. 1.

\section{Standard preparation}

Stock solution of NP (Sigma Aldrich, USA) was prepared by dissolving $10 \mathrm{mg}$ in $10 \mathrm{ml}$ ethyl acetate (Merck, Mumbai, India). Working solutions for calibration and recovery check were prepared by diluting the stock solutions at required concentrations in ethyl acetate.

\section{Extraction \\ Solid phase extraction (SPE)}

Extraction of NP from water samples was performed according to the method of Selvaraj et al. (2014). Preceding to extraction, the water samples (1 l) were filtered through Whatman no.1 filter paper and the $\mathrm{pH}$ was adjusted to 3 (1:1 v/v sulfuric acid (Merck, Mumbai, India)) for the better recovery of the target compounds. The C18-E cartridges (Phenomenex, California, USA) were conditioned with $10 \mathrm{ml}$ of ethyl acetate followed by methanol and ultrapure water in sequence using a vacuum manifold (Phenomenex, California, USA). Conditioning was carried out carefully avoiding drying of cartridge. Later, the water sample was passed through the cartridge at a flow rate of $5 \mathrm{ml} / \mathrm{min}$ and vacuum dried. Consequently, the cartridges were eluted with $20 \mathrm{ml}$ of ethyl acetate. Finally, the extract was condensed to few milliliters using rotavapour (Buchi 


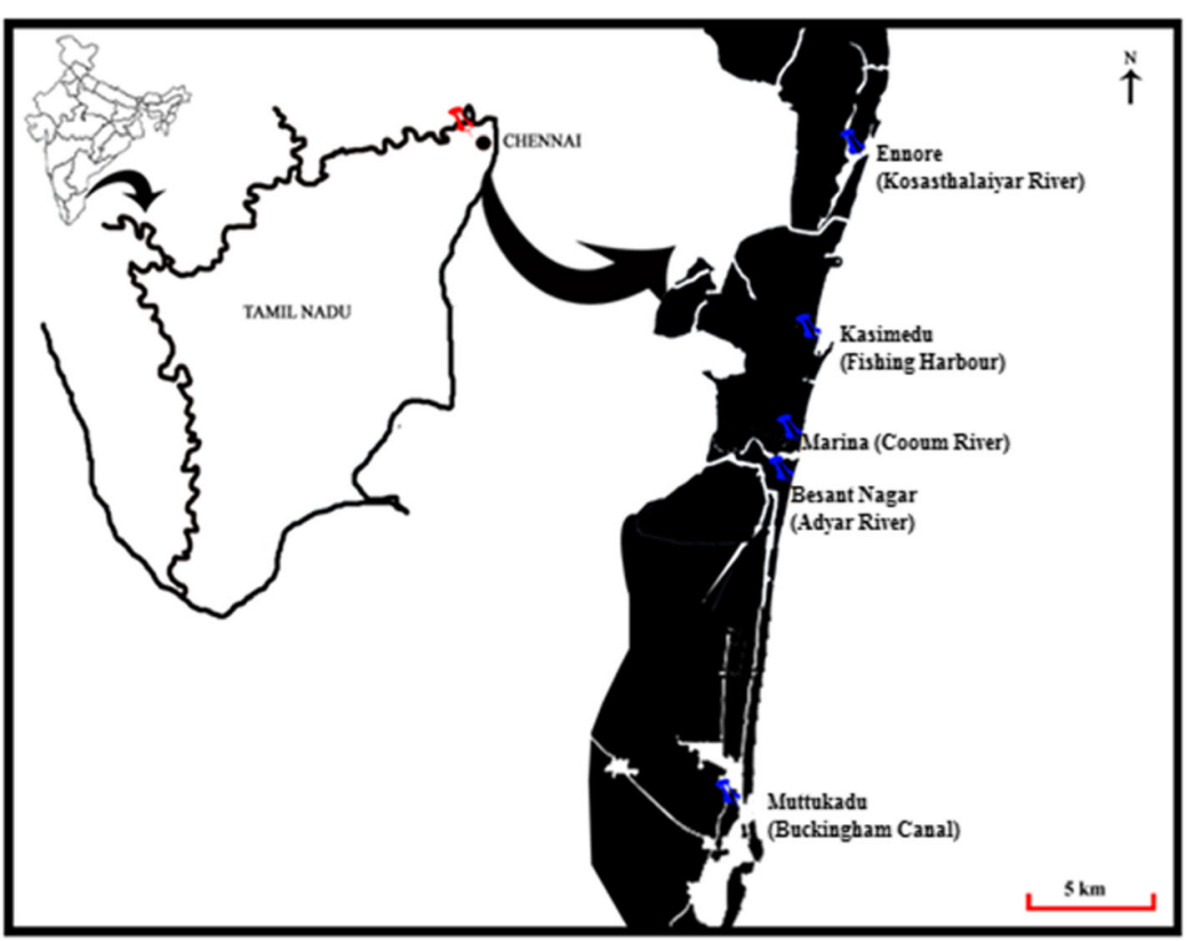

Fig. 1 Study area map

R-210, Switzerland) at $35^{\circ} \mathrm{C}$ and to $1 \mathrm{ml}$ by purging gently with nitrogen gas (99.999\%), and transferred to $2 \mathrm{ml}$ glass vial (Agilent technologies, Waldbromm, Germany) for derivatization.

\section{Liquid phase extraction (LPE)}

Extraction of nonylphenol from sediment samples was carried based on the protocol of Liao et al. (2012) with a slight modification. About $5 \mathrm{~g}$ of wet sediment was weighed and shaken in a mechanical shaker by adding 10 $\mathrm{ml}$ of methanol. Further, it was centrifuged at $3000 \mathrm{rpm}$ for $15 \mathrm{~min}$, and the supernatant was collected; the procedure was repeated twice, and the final supernatant was condensed to $15 \mathrm{ml}$, dissolved in $100 \mathrm{ml}$ of Milli-Q water, run through the C18 cartridges as water samples, and finally eluted with methanol and condensed as earlier.

\section{Derivatization}

Nonylphenol being slightly polar, prior to gas chromatogram coupled mass spectrum (GC-MS) analysis the extracts were derivatized, using $N$-methyl- $N$-trimethylsilyltrifluroacetamide (MSTFA) to increase the volatilization of the analytes. Fifty microliters of MSTFA was added to $1 \mathrm{ml}$ of working standard/sample extract and incubated at $70{ }^{\circ} \mathrm{C}$ for $30 \mathrm{~min}$ prior to GC-MS analysis for derivatization.

\section{Instrumentation}

\section{Operating conditions}

Gas chromatograph (GC-2010) interfaced with quadrupole mass spectrometer (QP-2010) was used to identify the target compound in water and sediment extracts using 99.999\% pure Helium as the carrier gas with a flow rate of $1 \mathrm{ml} / \mathrm{min}$. One microliter of the derivatized sample extract was injected into splitless mode using an auto injector $\left(290^{\circ} \mathrm{C}\right)$. The maximum oven temperature was raised up to $320^{\circ} \mathrm{C}$, and the separation was achieved using RTX-DB5 fused silica capillary column. The compound was identified based on the unique retention time and mass spectra obtained from full scan acquisition mode $(m / z 50-500)$.

\section{Quality assurance and quality control (QA/QC)}

Ultrapure water $(1000 \mathrm{ml})$ was spiked separately with 100 $\mathrm{ng} / \mathrm{ml}$ of the nonylphenol standards extracted, derivatized, and quantified to determine the linearity, mean recovery, precision (\%RSD), limit of detection (LOD), and limit of quantification (LOQ). There was $89 \%$ of recovery of nonylphenol from the spiked ultrapure water by following the procedures. The linear regression gave a good fit $R^{2}=0.999$.

\section{Results and discussion}

Nonylphenol in surface water

The distribution of nonylphenol in the surface water showed a varied pattern based on the degree of 
contamination (Fig. 2). Maximum concentration of $7.24 \pm 0.39 \mu \mathrm{g} / \mathrm{l}$ was recorded in the closed circuit of Muttukadu backwaters which might be due to the sand bar formation at the time of collection of water sample where seawater was not available for dilution. Ennore creek and Marina measured about $4.06 \pm 0.11 \mu \mathrm{g} / \mathrm{l}$ and $3.22 \pm 0.03 \mu \mathrm{g} / \mathrm{l}$ respectively. Comparatively, low levels of nonylphenol were found in Kasimedu and Besant Nagar $(2.05 \pm 0.22 \mu \mathrm{g} / \mathrm{l}$ and $1.83 \pm 0.26 \mu \mathrm{g} / \mathrm{l})$ (Fig. 2). Least concentration of nonylphenol was detected in the surface waters of Ennore mouth $(1.22 \pm 0.06 \mu \mathrm{g} / \mathrm{l})$.

In water, these compounds undergo photo- and biodegradation to form more persistent compound, nonylphenol (Corvini, Schäffer, \& Schlosser, 2006). Nonylphenols in comparison with their parent compound are more stable as their ultimate breakdown to $\mathrm{CO}_{2}$ and $\mathrm{H}_{2} \mathrm{O}$ proceeds slowly; because of the slow breakage of the phenol ring, it exerts more toxic effects on the aquatic organisms (Folmar et al., 2002). The domestic and industrial waste water as well as the surface runoff could possibly be the sources of NP in the aquatic environment. There might be a direct relationship between the levels of nonylphenol and the presence of urbanization near the sampling points. The concentration was found to be high in Muttukadu due to inadequately treated and untreated domestic waste water along with the continuous input of enormous magnitude of contaminants from Buckingham canal, boating activities, and closure of mouth due to sandbar formation which forms a closed network of estuarine system thereby increasing the levels of NP in the water. The concentrations of pollutants increase in environments due to discharge without proper treatment (Pojana, Gomiero, Jonkers, \& Marcomini, 2007). In spite of water being treated at some points in Adyar and Cooum rivers, these treatment plants cannot treat NPEs as it is used widely in both industrial and commercial products such as detergents, paints, and adhesives which end up in these rivers, while Kovalam located in close proximity of Muttukadu in the outskirts of Chennai is least contaminated site and considered as control site in many investigations (Vasanthi, Revathi, Arulvasu, \& Munuswamy, 2012). Later, when the estuary mouth is dredged with the sudden influx of seawater, this high concentration of NP would be mixed into the coastline which might have an impact on the surrounding coastline. The second highest concentration was recorded in Ennore creek which is also fed by the Buckingham canal, connected to Pulicat brackish water lake on the northern side and Kosasthalaiyar River, which is polluted due to high rates of anthropogenic activities. Similar to creeks in the other countries like those in Netherlands (Jonkers, Laane, \& de Voogt, 2003), Singapore had comparatively lower concentration of about 0.3 to $1 \mu \mathrm{g} / \mathrm{l}$ of the compound (Basheer, Parthiban, Jayaraman, Lee, \& Valiyaveettil, 2005) compared to Ennore creek which retains quite a high concentration of $4.03 \pm 0.11 \mu \mathrm{g} / \mathrm{l}$. Ennore creek which once nurtured rich fauna and flora, including the pristine mangroves, has now declined to a great extent because of several devastating effects arising due

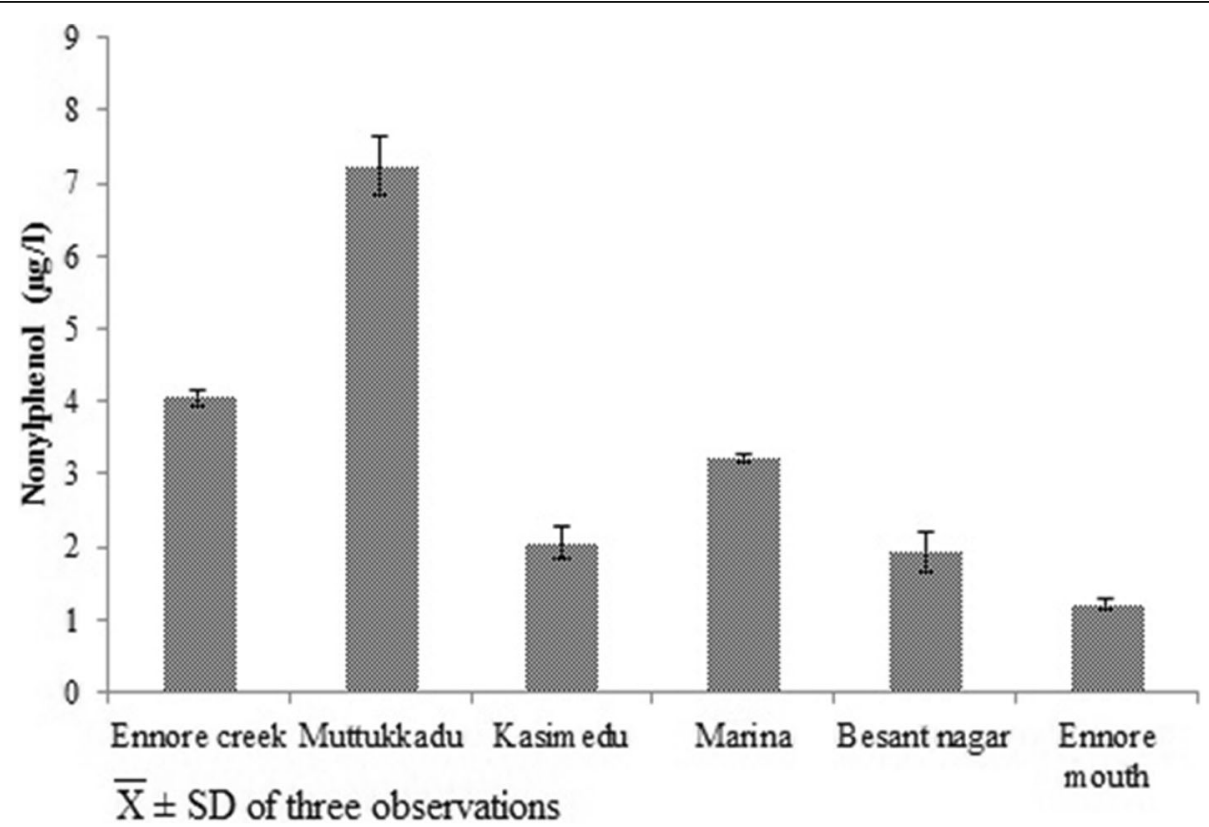

Fig. 2 Concentration of nonylphenol in water samples collected from six stations 
to human household and industrial activities, which includes a thermal power plant situated nearby that has imparted severe stress on the estuarine ecosystem (Jayaprakash, Srinivasalu, Jonathan, \& Mohan, 2005).

At Ennore estuary, despite the detection of high concentration of nonylphenol in creek, it has the least concentration detected in the mouth region of the estuary; the same phenomenon was reported in Saemangeum Bay, Korea, where the concentration of NP was found to be the highest in the estuary and was very low towards the open sea because of the dilution effect ( $\mathrm{Li}$ et al., 2005). Nonylphenol in water samples from Marina measured $3.22 \pm 0.05 \mu \mathrm{g} / \mathrm{l}$; being an important tourist destination with human activities, severe stress is imposed on the coastline. However, Cooum River remains as the most imperative source of nonylphenol in Marina. It has been noted earlier that Cooum receives a sizeable quantity of sewage from nearby areas for disposal. Waste water from household industries, slum settlements, agriculture runoffs, and detergents due to laundry washing remains as the source of contamination (Bunch, 1997). Comparatively, a lower concentration of nonylphenol was documented in Kasimedu and Besant Nagar coastal waters because of the reduced urban household activities like the release of detergents which are the chief contributors of the compound and especially in Besant Nagar where there is no direct contamination of the coastal waters other than from the comparatively less polluted Adyar River. The levels of nonylphenol also varied among the countries, and the concentration along the Chennai coast is higher than other international counterparts. In many Asian countries, NP levels in marine waters were usually higher than the western world (Duong et al., 2010). Studies have reported that nonylphenol remains as the most important compound in contamination of marine waters, especially those among the estrogenic compounds. An average concentration of $104 \mathrm{ng} / \mathrm{l}$ of nonylphenol was reported along the Tokyo bay (Hashimoto et al., 2005), $0.42 \pm 0.16 \mu \mathrm{g} / \mathrm{l}$ in the north pacific coast of USA, and 23 to $108 \mathrm{ng} / \mathrm{l}$ in the Korean bay. High levels of nonylphenol concentration in several locations reflect their relationship with the sewage discharge. More detergents due to washing of clothes, using showers with shower cream, and plastic ware in the sewage due to urbanization are the important sources of contaminations. Further, the elevated levels of this endocrine disruptor could be attributed to two different reasons, the prime being there is no proper efficacy of law in a country with a huge population and secondly, the country is experiencing a rapid economic growth of about $6.4 \%$ annually for the last two decades, which is placing a significant pressure on the environment due to rapid industrialization.

\section{Nonylphenol in sediment}

Due to its hydrophobic properties, NP in surface water tends to get adsorbed quickly by sediment particles which induced the preferential accumulation of nonylphenol in the sediments (Liao et al., 2012). Nonylphenol photo-degrades in sunlight, but its half-life in sediment is estimated to be more than 60 years (Soares, Guieysse, Jefferson, Cartmell, \& Lester, 2008). Nonylphenol concentration in the sediment samples was found to be high in comparison with the water samples in several places in both fresh and marine environment. A similar trend was observed in the current study, where the concentration of nonylphenol was higher in sediment than in the water samples. The levels were recorded in sediments as $30.96 \pm 0.39 \mu \mathrm{g} / \mathrm{kg}, 25.49 \pm 0.88 \mu \mathrm{g} / \mathrm{kg}, 13.23 \pm$ $1.40 \mu \mathrm{g} / \mathrm{kg}, \quad 9.75 \pm 0.74 \mu \mathrm{g} / \mathrm{kg}, \quad 8.33 \pm 0.92 \mu \mathrm{g} / \mathrm{kg}, \quad$ and $3.31 \pm 0.48 \mu \mathrm{g} / \mathrm{kg}$ in Muttukadu, Ennore creek, Marina, Kasimedu, Besant Nagar, and Ennore respectively (Fig. 3). In general, environmental matrices such as sediments contain complex residues of organic compounds of both natural and anthropogenic origin. The concentration and toxic potencies of compounds present in such complex mixtures can range over several orders of magnitude and can be modulated by interactions among chemicals that affect the levels of individual compounds. Also, the mobility of nonylphenol is lower in case of such non-porous sediments.

The levels of nonylphenol in the backwaters of Muttukadu $(30.96 \pm 0.34 \mu \mathrm{g} / \mathrm{kg})$ and Ennore creek $(25.49 \pm$ $0.88 \mu \mathrm{g} / \mathrm{kg}$ ) were found to be relatively higher than that in the other places. The accumulation of compound in sediments depends on various factors like the nature of soil, climate, and microfauna in the sediments. Sediment texture affects the concentration of nonylphenol to a very great extent. Certain sediments which are muddy and clayey tend to accumulate the compound more rapidly due to their adsorptive properties. The sediments collected from Muttukadu and Ennore creek were clayey; in addition, the estuarine sediments are particularly likely to retain nonylphenol due to its slow rate of degradation and low mobility in non-porous sediments; hence, high concentration of NP was detected. With half-life ranging from several years to decades, the fauna of the soil which regulates the anaerobic degradation of the compound is also responsible for its breakdown (Ying, Williams, \& Kookana, 2002). In contrast, the sandy soils are comparatively poor accumulators of nonylphenol as they allow the mobility of the compound due to their porous nature. This could be the reason for the low concentration of the compound in Besant Nagar and Ennore where NP is dissolved back into the water with least accumulation. In spite of the sandy nature, Marina and Kasimedu sediments have accumulated a considerable amount of 


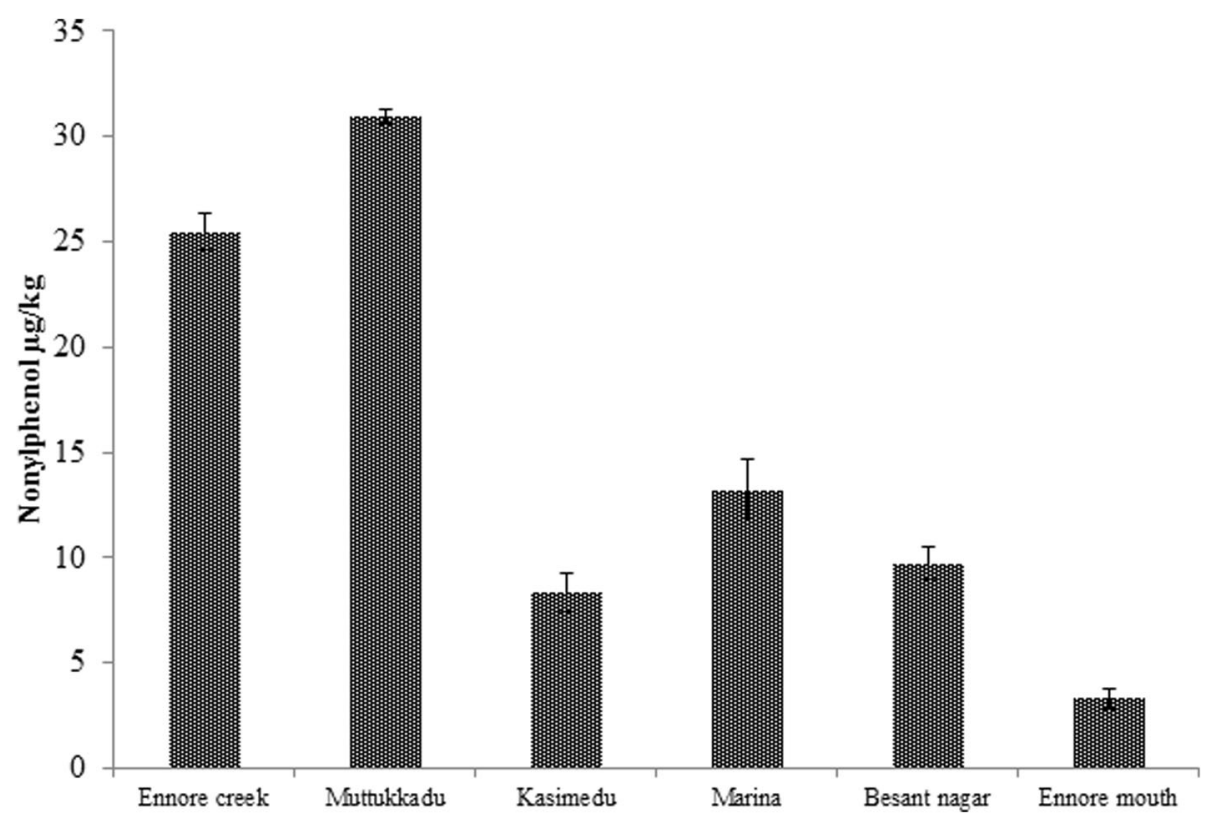

Fig. 3 Concentration of nonylphenol in sediment samples collected from six stations

nonylphenol which could be due to the stressful anthropogenic activity in the beach and Cooum which carries only drainage rather than water except during the monsoons (Bunch, 1997). Kasimedu is one of the major fishing grounds for catching fishes and crustaceans in Chennai. The breakwater inside the harbor leads up to $300 \mathrm{~m}$ into the sea and also serves in ship building. Several oil and antifouling paints used in the boats contain nonylphenol (Agency, 2010) and might have been the source of nonylphenol contamination in the Kasimedu sediments.

High accumulation of nonylphenol made the sediments a long-term pollutant sink and reservoir. The adsorbed compounds can be released into the water phase and become the source of contaminants when hydraulic regimes of the water change (Mao et al., 2012). De Weert, Viñas, Grotenhuis, Rijnaarts, and Langenhoff (2010) reported that nonylphenol in water phase was comparatively more available for biodegradation than in the sediments. The effects of changing conditions on desorption and biodegradation processes are essential for adequate prediction on the fate of pollutants and the ecological effect of the polluted sediments.

Most of the ecotoxicological studies are focused on heavy metal accumulation and their effects and thereby overlook many other endocrine disrupting compounds which might be the plausible explanation for the increased levels of nonylphenol and several other EDCs in the environment.

\section{Conclusion}

The results support that the nonylphenol has now reached the level of affecting the aquatic lives. Nonylphenol can be predicted to increase in levels in all the possible matrices, even in human community in the near future as the compounds can moderately biomagnify. However, further studies are necessary to investigate the potential ecological health effects of these compounds.

\section{Additional file}

Additional file 1: Excel sheet. (XLSX $19 \mathrm{~kb})$

\section{Abbreviations}

APEOs: Alkylphenol ethoxylates; ED: Endocrine disruptor; EDCs: Endocrine disrupting compounds; GC-MS: Gas chromatogram coupled mass spectrum; LOD: Limit of detection; LOQ: Limit of quantification; MSTFA: N-Methyl-Ntrimethylsilyltrifluroacetamide; NP: Nonylphenol; NPEs: Nonylphenol ethoxylates; OPEs: Octylphenol ethoxylates; US EPA: United States Environmental protection agency

\section{Acknowledgements}

We are extremely grateful to Dr. Naboyoshi Yamashita, AIST, Japan, for providing us with extraction unit. We are indebted to University Grants Commission (UGC) Non-Net Fellowship for providing financial assistance to Mrs. R. Subha.

\section{Funding}

The first author was funded with UGC-NON NET Fellowship awarded by University Grants Commission, New Delhi. The funding was used for travel and collection of samples and for buying respective chemicals for the research work.

Availability of data and materials Excel sheet attached in Additional file 1. 


\section{Declaration}

We the above authors confirm that this research work is not submitted elsewhere for publication, and further, we declare this is an original research.

\section{Authors' contributions}

SR and MS contributed to the sample processing, preparation, extraction, instrumentation, and analysis. KG and TS contributed to the sampling and manuscript correction and preparation. MN contributed to the research guide. All authors read and approved the final manuscript.

\section{Authors' information}

Dr. Subha Raju—Assistant Professor, Mohamed Sathak College of Arts and Science, Chennai, India

Madhumathi Sivamurugan_completed M.Phil degree, Chennai

Karuna Gunasagaran—Scientist D, ENVIS Center, University of Madras, Chennai, India

Thirunavukkarasu Subramani-Research scholar, University of Madras

Munuswamy Natesan—UGC-BSR, Faculty fellow, University of Madras, Chennai

\section{Ethics approval and consent to participate}

Not applicable

\section{Consent for publication}

Not applicable

\section{Competing interests}

The authors declare that they have no competing interests.

\section{Publisher's Note}

Springer Nature remains neutral with regard to jurisdictional claims in published maps and institutional affiliations.

Received: 19 June 2017 Accepted: 6 November 2018

Published online: 05 December 2018

\section{References}

Agency, U. S. E. P. (2010). Nonylphenol (NP) and nonylphenol ethoxylates (NPES) action plan, (p. 13)

Basheer, C., Parthiban, A., Jayaraman, A., Lee, H. K., \& Valiyaveettil, S. (2005). Determination of alkylphenols and bisphenol-A: A comparative investigation of functional polymer-coated membrane microextraction and solid-phase microextraction techniques. Journal of Chromatography A, 1087, 274-282.

Bunch, M. J. (1997). The potential role of geographic information systems and simulation modelling in the environmental management of the Cooum River. Chennai Information Studies, 3, 22.

Corvini, P., Schäffer, A., \& Schlosser, D. (2006). Microbial degradation of nonylphenol and other alkylphenols-Our evolving view. Applied Microbiology and Biotechnology, 72, 223-243.

De Weert, J., Viñas, M., Grotenhuis, T., Rijnaarts, H., \& Langenhoff, A. (2010). Aerobic nonylphenol degradation and nitro-nonylphenol formation by microbial cultures from sediments. Applied Microbiology and Biotechnology, $86,761-771$.

Duong, C. N., Ra, J. S., Cho, J., Kim, S. D., Choi, H. K., Park, J.-H., ... Kim, S. D. (2010). Estrogenic chemicals and estrogenicity in river waters of South Korea and seven Asian countries. Chemosphere, 78, 286-293.

Folmar, L. C., Hemmer, M. J., Denslow, N. D., Kroll, K., Chen, J., Cheek, A., ... Grau, E. G. (2002). A comparison of the estrogenic potencies of estradiol, ethynylestradiol, diethylstilbestrol, nonylphenol and methoxychlor in vivo and in vitro. Aquatic Toxicology, 60, 101-110.

Hashimoto, S., Horiuchi, A., Yoshimoto, T., Nakao, M., Omura, H., Kato, Y., ... Giesy, J. (2005). Horizontal and vertical distribution of estrogenic activities in sediments and waters from Tokyo Bay, Japan. Archives of Environmental Contamination and Toxicology, 48, 209-216.

Jayaprakash, M., Srinivasalu, S., Jonathan, M., \& Mohan, V. R. (2005). A baseline study of physico-chemical parameters and trace metals in waters of Ennore Creek, Chennai, India. Marine Pollution Bulletin, 50, 583-589.

Jim Carlisle, D. V. M., David Chan, D., Page Painter, M. D., \& Wu, L. (2009). Toxicological profile for nonylphenol. California Environmental Protection Agency. http://www. opc.ca.gov/webmaster/ftp/project_pages/MarineDebris_OEHHA_ToxProfiles/ Bisphenol\%20A\%20Final.pdf. Accessed June 2014
Jonkers, N., Laane, R. W., \& de Voogt, P. (2003). Fate of nonylphenol ethoxylates and their metabolites in two Dutch estuaries: evidence of biodegradation in the field. Environmental Science \& Technology, 37, 321-327.

Selvaraj, K. K., Shanmugam, G., Sampath, S., Larsson, D. J., \& Ramaswamy, B. R. (2014). GC-MS determination of bisphenol A and alkylphenol ethoxylates in river water from India and their ecotoxicological risk assessment. Ecotoxicology and environmental safety, 99, 13-20.

Li, D., Dong, M., Shim, W. J., Hong, S. H., Oh, J.-R., Yim, U. H., ... Cho, S. R. (2005). Seasonal and spatial distribution of nonylphenol and IBP in Saemangeum Bay, Korea. Marine Pollution Bulletin, 51, 966-974.

Liao, C., Liu, F., Moon, H.-B., Yamashita, N., Yun, S., \& Kannan, K. (2012). Bisphenol analogues in sediments from industrialized areas in the United States, Japan, and Korea: spatial and temporal distributions. Environmental Science \& Technology, 46, 11558-11565.

Mao, Z., Zheng, X.-F., Zhang, Y.-Q., Tao, X.-X., Li, Y., \& Wang, W. (2012). Occurrence and biodegradation of nonylphenol in the environment. International Journal of Molecular Sciences, 13, 491-505.

Nair-Menon, J. U., Campbell, G. T., \& Blake, C. A. (1996). Toxic effects of octylphenol on cultured rat and murine splenocytes. Toxicology and Applied Pharmacology, 139, 437-444.

Pojana, G., Gomiero, A., Jonkers, N., \& Marcomini, A. (2007). Natural and synthetic endocrine disrupting compounds (EDCs) in water, sediment and biota of a coastal lagoon. Environment International, 33, 929-936.

Renner, R. (1997). European bans on surfactant trigger transatlantic debate. Environmental Science \& Technology, 31, 316A-320A.

Soares, A., Guieysse, B., Jefferson, B., Cartmell, E., \& Lester, J. (2008). Nonylphenol in the environment: a critical review on occurrence, fate, toxicity and treatment in wastewaters. Environment International, 34, 1033-1049.

Soto, A. M., Justicia, H., Wray, J. W., \& Sonnenschein, C. (1991). p-Nonyl-phenol: an estrogenic xenobiotic released from "modified" polystyrene. Environmental Health Perspectives, 92, 167.

Tabb, M. M., \& Blumberg, B. (2006). New modes of action for endocrinedisrupting chemicals. Molecular Endocrinology, 20, 475-482.

Vasanthi, L. A., Revathi, P., Arulvasu, C., \& Munuswamy, N. (2012). Biomarkers of metal toxicity and histology of Perna viridis from Ennore estuary, Chennai, south east coast of India. Ecotoxicology and Environmental Safety, 84, 92-98.

White, R., Jobling, S., Hoare, S., Sumpter, J., \& Parker, M. (1994). Environmentally persistent alkylphenolic compounds are estrogenic. Endocrinology, 135, 175-182.

Ying, G.-G., Williams, B., \& Kookana, R. (2002). Environmental fate of alkylphenols and alkylphenol ethoxylates-a review. Environment International, 28, 215-226.

\section{Submit your manuscript to a SpringerOpen ${ }^{\circ}$ journal and benefit from:}

- Convenient online submission

- Rigorous peer review

- Open access: articles freely available online

High visibility within the field

- Retaining the copyright to your article

Submit your next manuscript at $\boldsymbol{\nabla}$ springeropen.com 